\title{
Larynx: The Complex Gateway to the Lungs
}

The role played by the upper airways when using coughenhancement techniques in patients with neuromuscular disorders has been subject to increasing interest in recent years. The work by Lachal and colleagues, ${ }^{1}$ published in this issue of RESPIRATORY CARE, contributes significantly to these discussions.

The upper airways are part of a comprehensive and vitally important system ensuring efficient passage of airflow to the lungs at the lowest possible energy cost, while simultaneously preventing liquids and solids from entering the bronchial tree. In respiratory therapy, the larynx has become increasingly recognized as an important potential source for air-flow obstruction; thus, a malfunctioning larynx might set the agenda for restricted air-flow delivery to the lungs. ${ }^{2}$

Surprisingly, researchers and clinicians alike have tended to ignore the importance of the larynx in the respiratory system, appearing to see it merely as a passive opening at its inlet. We need to acknowledge that the larynx is a highly complex valve that carefully modulates and safeguards the entrance to the bronchial tree. It is abundantly equipped with afferent sensory nerves, complex neuromuscular interactions, and reflex mechanisms ensuring fine-tuned motor responses to a variety of potential exposures. The larynx plays a key role in controlling air-flow resistance during exercise, it protects the lungs from aspiration, it performs precise movements in phonation and singing, and it is crucially important to perform effective cough. . $^{3-6}$

It is in this context that we read the work by Lachal and colleagues. ${ }^{1}$ The authors have constructed an in vitro model to explore the role played by the upper airways while using the mechanical insufflation-exsufflation (MI-E) cough-enhancement technique. MI-E is widely used in patients with neuromuscular disorders to assist and augment cough mechanically by applying positive and negative pressure changes to the airways. The rapid conversion from positive to negative pressures simulates the changes in

\footnotetext{
The authors have disclosed no conflicts of interests.
}

Correspondence: Tiina M Andersen PT PhD, Norwegian Advisory Unit on Home Mechanical Ventilation, Thoracic Department, Haukeland University Hospital, 5021 Bergen, Norway. E-mail: tiina.andersen@ helse-bergen.no.

DOI: $10.4187 /$ respcare.06989 air-flow that occur during normal cough, thereby increasing peak cough air-flow and facilitating clearance of secretions in the airways. ${ }^{7-13}$ Difficulties relating to upper airway function are frequently encountered when applying MI-E in patients with amyotrophic lateral sclerosis (ALS) with bulbar innervated muscular dysfunction, ${ }^{14-17}$ and these

\section{See the Original Study on Page 752}

patients have been particularly challenging to treat, ${ }^{10,13,18,19}$ allegedly due to disturbed laryngeal responses. ${ }^{20-22}$ Lachal and colleagues constructed their model with the intent to simulate upper airway air-flow responses to MI-E by inserting a collapsible latex tube $(15 \mathrm{~cm}$ long, $18 \mathrm{~mm}$ wide, and $1 \mathrm{~mm}$ thick) into a circuit between the MI-E device and a lung model with adjustable resistance and compliance. ${ }^{1}$ They hypothesized that the collapsible tube would reduce peak expiratory flow (PEF) during the exsufflation phase. They used several resistance-compliance models to imitate a number of conditions in the respiratory system. Key findings were that for every compliance-resistance condition tested, PEF was higher with the collapsible tube inserted than without, and that the generation of PEF occurred within the first $100 \mathrm{~ms}$ of the exsufflation phase. ${ }^{1}$

Flow is movement of matter within a confined configuration, induced by pressure differences. For example, airflow is created by an air pressure at one end, and another air pressure at the other end. As air-flow exceeds a critical velocity, or if the air-flow geometry becomes more turbulent, the pressure will drop and the air-flow will cause deformations in the structure within which it takes place. Furthermore, deformations in that structure will affect the air-flow, and these processes can be categorized as "fluid (or gas)-structure interactions." ${ }^{23}$ This is what Lachal and colleagues examined in their study. ${ }^{1}$ The pressures from the MI-E device creates air-flow in the latex tube, which deforms the structure of the tube and thus affects the airflow. The authors illustrate this phenomenon nicely with figures and a video, and they show us that these dynamic changes in the configuration of the tube increased the PEF measured at the other end. Thus, structural changes caused by the air-flow generated a new geometry for the airflow. ${ }^{23}$

Normal cough is a highly dynamic and compound maneuver that strongly involves the upper airways. As the 


\section{EDITORIALS}
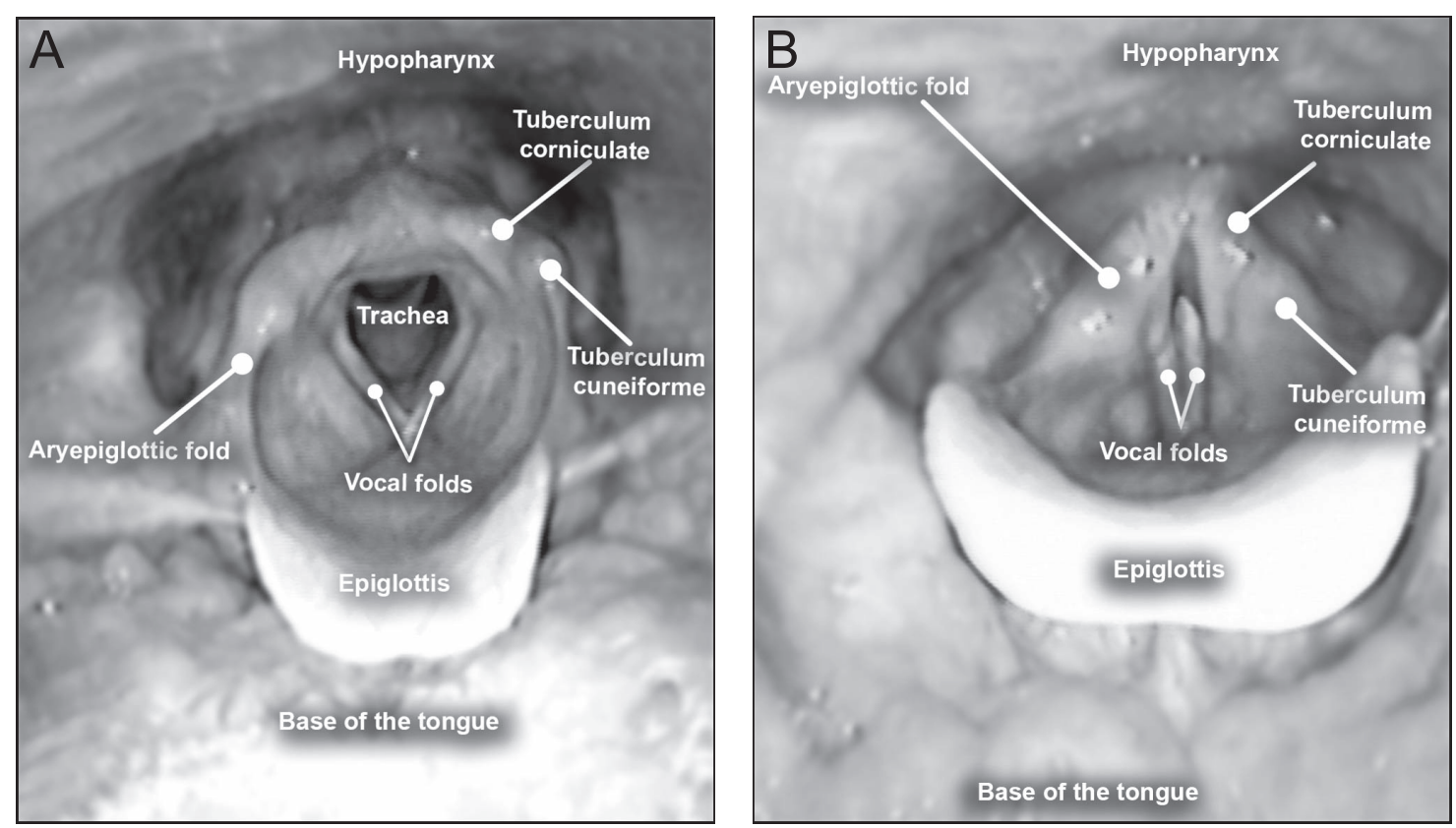

Fig. 1. Top view of the larynx. A: Open glottis during deep inspiration. B: Closed glottis during laryngeal closing phase to enable the build-up of intrathoracic driving pressure.

authors point out, normal cough starts with an initial laryngeal abduction that allows air to enter the lungs during a deep inspiration, followed by a rapid laryngeal closing phase to enable an increase in intrathoracic driving pressure (see Fig. 1 for illustrations of open and closed glottis during normal cough). A secondary abrupt laryngeal abduction will then result in a high expiratory air-flow, ${ }^{24}$ which will create "fluid-structure interactions" within the upper airway. In healthy individuals, the laryngeal cough responses to MI-E are basically as described above. ${ }^{20} \mathrm{Sev}-$ eral "fluid-structure interactions" have been described in the upper airways during MI-E maneuvers, such as retroflex movements of the epiglottis that more or less cover or flutter over the laryngeal inlet during the positive pressure cycles, hypopharyngeal constriction during the negativepressure cycles, as well as adduction of supraglottic structures during positive-pressure cycles in bulbar ALS patients. ${ }^{20,21}$ How these dynamic laryngeal movements affect air-flow geometry in the large conductive airways is yet to be explored.

Lachal and colleagues found that the generation of PEF occurred within the first $100 \mathrm{~ms}$ of the exsufflation phase. ${ }^{1}$ Cough peak flow value has been the main outcome in previous MI-E effect studies. Some years ago, Lacombe et $\mathrm{al}^{25}$ proposed a new outcome for MI-E efficiency: effective cough time (ie, the time spent above a cough peak flow that is required to move secretions effectively), thereby suggesting that there might be a clinically relevant efficacy factor that is time-dependent. This idea has unfortunately received little attention in subsequent research. We encourage future studies to explore whether the combination of duration and the level of the cough peak flow is clinically important.

As Lachal and colleagues correctly point out, contrary to the latex tube they used in their experiments, the upper airways are complex and partially active structures, with the larynx guarding the entrance to the bronchial tree. ${ }^{1}$ Structurally, the upper airways consist of several tissues of varying solidity (ie, rigid cartilage skeletons, ligaments, muscles, and soft mucous membranes). ${ }^{3}$ Functionally, laryngeal muscles are under voluntary and involuntary (reflex) control.6,26 Important functions such as phonation, swallowing, breathing, and coughing require synchronized and fine-tuned movements, utilizing a shared innervation. Moreover, the larynx moves upward and downward when delivering on its varying tasks, and laryngeal structures move in relation to each other and interact in a complex manner, but always in concert. ${ }^{6,27}$ The vagal nerve ensures the larynx and the diaphragm act in concert by stimulating the abducting muscle of the larynx immediately before diaphragmatic contraction. ${ }^{28}$ Neuromuscular disorders such as ALS therefore impair laryngeal function due to malfunctioning sensory afferent nerves and abnormal reflex responses, as well as to poor muscle coordination or weakness or spasms. ${ }^{14-17,29,30} \mathrm{We}$ are far from understanding these complex interplays, both in health and disease.

The work by Lachal and colleagues ${ }^{1}$ has set the stage for development of future models that can simulate airway flow in patients with devastating progressive and fatal neuromuscular disorders, aiming to improve the technical 


\section{EDITORIALS}

equipment we have at hand to enhance their ability to cough. The authors and RESPIRATORY CARE are to be complimented for bringing this issue to the research agenda. As the authors point out, we need to acknowledge the high degree of uncertainty embedded in their results. The model is in no way capable of reproducing the complex and dynamic structures that constitute the human upper airways. Specifically, the model is unsuited to represent "fluid (or gas)-structure interactions" in living human individuals. The human upper airways will be challenging to model both in health and disease, including with attached animal or human cadaver models as Lachal and colleagues suggest in their article, ${ }^{1}$ or with 3 -dimensional printing already available. To produce data that can be assumed to reflect real-life clinical scenarios, we would need to know the tissue properties of the relevant organ structures, such as elasticity and compliance, and we would have to understand the reflex and muscle responses that are involved. We do not have that kind of knowledge yet. In future research, computer-based simulation will likely take the place of physical experiments.

Our own clinical experience is mainly linked to the larynx, and we are not experts on tracheal conditions. However, the latex tube model may apply to patients with tracheomalacia, where "passive excessive collapsibility" might be more relevant. MI-E has not been studied in tracheomalacia, although it has been speculated that the increased air-flow may result in an aerodynamically induced collapse, and therefore caution is warranted. If a collapsible trachea acts like the collapsible latex tube, one may speculate that MI-E can increase cough peak flow and potentially lead to better clearing of secretions. On the other hand, higher inspiratory flow values could induce inspiratory collapse and thus reduce pulmonary volume, which of course would be counterproductive.

An important take-home message from the study by Lachal and colleagues ${ }^{1}$ could be that complex "fluid-structure interactions" operate in the upper airways. As we perform respiratory therapy in patients with neuromuscular disorders, we do not really know the significance of such interactions, how they might obstruct treatment efforts, or whether we may utilize them to the benefit of our patients. Moreover, we should acknowledge that the upper airways, and especially the larynx, must be seen as an active and dynamic gateway to the lower airways, guarding the entrance to the lungs in complex manners that we still do not fully understand or pay much attention to. For example, during noninvasive mechanical ventilation, we are deeply concerned about mask leaks, but we tend to pay less attention to what happens to the air-flow as it progresses through the airway. In a clinical context, flexible laryngoscopy during ongoing noninvasive ventilation or MI-E appears a reasonable approach to visualize the response of the upper airway structures in patients who do not respond to treatment as expected. Such visual information has already guided the therapeutic approach to "difficult patients" in our own clinical units. Flow and pressure measurements can be added to this setup and will aid us in understanding the interplay between upper airway structures and externally applied pressures and flows, and specifically how upper airway responses to MI-E or noninvasive ventilation might affect the air-flow geometry. The ultimate goal would be to develop customized settings based on proper understanding of these issues in individual patients. ${ }^{20-22,31,32}$ Until now, too many of our endeavors in this arena have been based on presumptions and so-called expert opinions, and not on solid evidence. We strongly encourage future research in this area to the benefit of patients afflicted by devastating and often progressive neuromuscular disorders.

\section{ACKNOWLEDGMENTS}

The authors extend their thanks to medical photographer Thor-Andre Ellingsen for his valuable help with the image and to engineer Maren Roll Lied for valuable advice in physics.

Tiina M Andersen
Thomas Halvorsen
Ove Fondenes
John-Helge Heimdal
Ola D Røksund
Maria Vollsæerer
Haukeland University Hospital, Bergen, Norway

\section{REFERENCES}

1. Lachal R, Louis B, Subtil F, Guerin C. Bench assessment of the effect of a collapsible tube on the efficiency of a mechanical insufflation-exsufflation device. Respir Care 2019;64(7):752-759.

2. Ferris BG, Jr., Mead J, Opie LH. Partitioning of respiratory flow resistance in man. J Appl Physiol 1964;19:653-658.

3. Pierce RJ, Worsnop CJ. Upper airway function and dysfunction in respiration. Clin Exp Pharmacol Physiol 1999;26(1):1-10.

4. Terzi N, Orlikowski D, Aegerter P, Lejaille M, Ruquet M, Zalcman $\mathrm{G}$, et al. Breathing-swallowing interaction in neuromuscular patients: a physiological evaluation. Am J Respir Crit Care Med 2007;175(3): 269-276.

5. Fretheim-Kelly Z, Halvorsen T, Heimdal JH, Strand E, Vollsaeter Zoe M, Clemm H, et al. Feasibility and tolerability of measuring translaryngeal pressure during exercise. Laryngoscope 2019. doi: 10.1002/lary.27846.

6. Ludlow CL. Laryngeal reflexes: physiology, technique, and clinical use. J Clin Neurophysiol 2015;32(4):284-293.

7. Chatwin M, Ross E, Hart N, Nickol AH, Polkey MI, Simonds AK. Cough augmentation with mechanical insufflation/exsufflation in patients with neuromuscular weakness. Eur Respir J 2003;21(3):502508.

8. Chatwin M, Simonds AK. The addition of mechanical insufflation/exsufflation shortens airway-clearance sessions in neuromuscular patients with chest infection. Respir Care 2009;54(11):1473-1479.

9. Fauroux B, Guillemot N, Aubertin G, Nathan N, Labit A, Clement A, et al. Physiologic benefits of mechanical insufflation-exsufflation 


\section{EDITORIALS}

in children with neuromuscular diseases. Chest 2008;133(1):161168.

10. Sancho J, Servera E, Diaz J, Marin J. Efficacy of mechanical insufflation-exsufflation in medically stable patients with amyotrophic lateral sclerosis. Chest 2004;125(4):1400-1405.

11. Winck JC, Gonçalves MR, Lourenço C, Viana P, Almeida J, Bach JR. Effects of mechanical insufflation-exsufflation on respiratory parameters for patients with chronic airway secretion encumbrance. Chest 2004;126(3):774-780.

12. Bach JR. Mechanical insufflation-exsufflation. Comparison of peak expiratory flows with manually assisted and unassisted coughing techniques. Chest 1993;104(5):1553-1562.

13. Mustfa N, Aiello M, Lyall RA, Nikoletou D, Olivieri D, Leigh PN, et al. Cough augmentation in amyotrophic lateral sclerosis. Neurology 2003;61(9):1285-1287.

14. Garcia-Pachon E, Marti J, Mayos M, Casan P, Sanchis J. Clinical significance of upper airway dysfunction in motor neurone disease. Thorax 1994;49(9):896-900.

15. Tomik J, Tomik B, Partyka D, Skladzien J, Szczudlik A. Profile of laryngological abnormalities in patients with amyotrophic lateral sclerosis. J Laryngol Otol 2007;121(11):1064-1069.

16. Hillel A, Dray T, Miller R, Yorkston K, Konikow N, Strande E, et al. Presentation of ALS to the otolaryngologist/head and neck surgeon: getting to the neurologist. Neurology 1999;53(8 Suppl 5):S22S25.

17. Roth CR, Glaze LE, Goding GS Jr, David WS. Spasmodic dysphonia symptoms as initial presentation of amyotrophic lateral sclerosis. J Voice 1996;10(4):362-367.

18. Bach JR. Amyotrophic lateral sclerosis: predictors for prolongation of life by noninvasive respiratory aids. Arch Phys Med Rehabil 1995;76(9):828-832.

19. Hanayama K, Ishikawa Y, Bach JR. Amyotrophic lateral sclerosis. Successful treatment of mucous plugging by mechanical insufflation-exsufflation. Am J Phys Med Rehabil 1997;76(4):338-339.

20. Andersen T, Sandnes A, Hilland M, Halvorsen T, Fondenes O, Heimdal $\mathrm{JH}$, et al. Laryngeal response patterns to mechanical insufflationexsufflation in healthy subjects. Am J Phys Med Rehabil 2013; 92(10):920-929.
21. Andersen T, Sandnes A, Brekka AK, Hilland M, Clemm H, Fondenes $\mathrm{O}$, et al. Laryngeal response patterns influence the efficacy of mechanical assisted cough in amyotrophic lateral sclerosis. Thorax 2017;72(3):221-229.

22. Andersen TM, Sandnes A, Fondenes O, Nilsen RM, Tysnes OB, Heimdal JH, et al. Laryngeal responses to mechanically assisted cough in progressing amyotrophic lateral sclerosis. Respir Care 2018; 63(5):538-549.

23. Tu J, Inthavong K, Ahmadi G. Computational Fluid and Particle Dynamics in the Human Respiratory System. New York: Springer Netherlands; 2013.

24. Leith DE. Cough. Phys Ther 48(5):439-447, 1968.

25. Lacombe M, Del Amo Castrillo L, Bore A, Chapeau D, Horvat E, Vaugier I, et al. Comparison of three cough-augmentation techniques in neuromuscular patients: mechanical insufflation combined with manually assisted cough, insufflation-exsufflation alone and insufflation-exsufflation combined with manually assisted cough. Respiration 2014;88(3):215-222.

26. Schweizer V, Dorfl J. The anatomy of the inferior laryngeal nerve. Clin Otolaryngol Allied Sci 1997;22(4):362-369.

27. Armstrong WB, Netterville JL. Anatomy of the larynx, trachea, and bronchi. Otolaryngol Clin North Am 1995;28(4):685-699.

28. Brancatisano TP, Dodd DS, Engel LA. Respiratory activity of posterior cricoarytenoid muscle and vocal cords in humans. J Appl Physiol Respir Environ Exerc Physiol 1984;57(4):1143-1149.

29. Woodson G. Management of neurologic disorders of the larynx. Ann Otol Rhinol Laryngol 2008;117(5):317-326.

30. Hadjikoutis S, Wiles CM. Respiratory complications related to bulbar dysfunction in motor neuron disease. Acta Neurol Scand 2001; 103(4):207-213.

31. Andersen TM, Sandnes A, Fondenes O, Clemm H, Halvorsen T, Nilsen RM, et al. Laryngoscopy can be a valuable tool for unexpected therapeutic response in noninvasive respiratory interventions. Respir Care 2018;63(11):1459-1461.

32. Toussaint M, Chatwin M, Gonzales J, Berlowitz DJ, ENMC Respiratory Therapy Consortium. 228th ENMC International Workshop: Airway clearance techniques in neuromuscular disorders. Naarden, The Netherlands, 3-5 Mar, 2017. Neuromuscul Disord 2018;28:289298. 